\title{
KEANEKARAGAMAN FITOPLANKTON PADA PERAIRAN CALON SUAKA PERIKANAN DI WADUK KOTO PANJANG, RIAU
}

\author{
Yayuk Sugianti, Adriani Sri Nastiti Krismono, dan Andri Warsa \\ Peneliti pada Loka Riset Pemacuan Stok Ikan, Jatiluhur-Purwakarta \\ Teregistrasi I tanggal: 26 Januari 2008; Diterima setelah perbaikan tanggal: 24 Maret 2008; \\ Disetujui terbit tanggal: 12 Januari 2009
}

\begin{abstract}
ABSTRAK
Salah satu kriteria penting untuk menentukan suatu lokasi menjadi suaka perikanan agar dapat berfungsi sebagai sumber benih untuk meningkatkan produksi ikan adalah ketersediaan pakan alami seperti plantkon. Tujuan dari penelitian ini untuk mengetahui komposisi, keanekaragaman, dan dominansi fitoplankton sebagai pakan alami ikan pada perairan calon suaka perikanan di Waduk Koto Panjang, Riau. Contoh diambil pada lima stasiun pengamatan pada bulan Maret, Juni, dan Desember 2007. Parameter yang dianalisis adalah komposisi dan kelimpahan, keanekaragaman, serta dominansi fitoplankton. Hasil pengamatan menunjukkan bahwa di Waduk Koto Panjang, Riau ditemukan lima kelas fitoplankton yaitu Chlorophyceae (21 marga), Cyanophyceae (tiga marga), Bacillariophyceae (tujuh marga), Dinophyceae (tiga marga), dan Euglenophyceae (dua marga) dengan total kelimpahan fitoplankton $6,6 \times 10^{5}$ ind. per L. Total nilai Indeks Keanekaragaman selama pengamatan adalah 2,97, berarti bahwa kondisi lingkungan di Waduk Koto Panjang sangat baik dan tidak tercemar. Terdapat tiga marga fitoplankton yang mendominansi yaitu Cosmarium, Staurastrum, dan Peridinium dengan nilai dominansi kumulatif masing-masing sebesar 26,54: 23,92; dan 13,37\%.
\end{abstract}

\section{KATAKUNCl: keanekaragaman, fitoplankton, Waduk Koto Panjang}

ABSTRACT: Phytoplankton diversity in inland fishery reserve candidate in Koto Panjang Reservoir, Riau. By: Yayuk Sugianti, Adriani Sri Nastiti Krismono, and Andri Warsa

One important criteria for selecting a site to be inland fishery reserve to increase fish seed production is the availability of natural food such as plankton. The objective of this study was to elucidate the composition, diversity, and dominancy of phytoplankton as natural food of fish in proposed site of inland fishery reserve of Koto Panjang Reservoir. The phytoplankton sample was taken in five stations at March, June, and December 2007. The Koto Panjang Reservoir had five classes of phytoplankton, namely Chlorophyceae (21 genus), Cyanophyceae (three genus), Bacillariophyceae (seven genus), Dinophyceae (three genus), and Euglenophyceae (two genus) with the total abundance of 6,6 $\times 10^{5}$ ind. per L. Total index of diversity of phytoplankton was 2.97, meaning that the Koto Panjang Reservoir was still in a good condition and unpolluted yet. There were three genera of phytoplankton dominating in the Koto Panjang Reservoir, namely Cosmarium, Staurastrum, and Peridinium at a respective dominancy cumulative index value of $26.54 \%$; 23.93; and 13.37 .

\section{KEYWORDS: diversity, phytoplankton, Koto Panjang Reservoir}

\section{PENDAHULUAN}

Waduk Koto Panjang yang terletak sebagian di Propinsi Riau dan sebagian lagi di Sumatera Barat, merupakan waduk yang berfungsi sebagai pembangkit listrik tenaga air, irigasi, wisata, dan perikanan. Waduk dengan luas 12.400 ha ini mendapatkan pasokan air dari Sungai Kampar Kanan, Kapau, Tiwi, Takus, Gulamo, Mahat, Osang, Cunding, Arau Kecil, dan Arau Besar (Nastiti et al., 2006). Waduk Koto Panjang merupakan waduk baru dan potensial, untuk itu perlu dilakukan pengelolaan sumber daya perikanan agar tetap terjaga kontinuitas peremajaan benih ikan ekonomis. Alternatif langkah untuk melestarikan plasma nutfah perikanan adalah dengan penyediaan suaka perikanan (fishery reserve). Penyediaan suaka perikanan merupakan salah satu cara pengelolaan sumber daya perikanan yang efektif dan efisien, karena secara langsung dapat melindungi dan meningkatkan sumber daya perikanan (Utomo et al., 2005).

Salah satu kriteria penting untuk menentukan suatu lokasi menjadi suaka perikanan agar dapat berfungsi sebagai sumber benih untuk meningkatkan produksi ikan di sekitarnya adalah ketersediaan pakan alami seperti plankton, bentos, perifiton, serangga air, dan buah pepohonan vegetasi reparian. Fitoplankton 
adalah kumpulan organisme yang selain memanfaatkan unsur-unsur hara, sinar matahari, dan karbondioksida, dapat juga memproduksi materi organik, memiliki klorofil yang berperan dalam proses fotosintesis untuk menghasilkan bahan organik dan oksigen dalam air (Wiadnyana \& Wagey, 2004). Sebagai dasar mata rantai pada siklus makanan di perairan daratan maupun bahari, fitoplankton menjadi makanan alami bagi zooplankton, baik yang kecil maupun yang dewasa. Selain itu, karena respon yang cepat terhadap perubahan lingkungan, menyebabkan fitoplankton dapat juga digunakan sebagai indikator kualitas air. Hanya jenis fitoplankton yang mempunyai daya toleransi tinggi yang dapat hidup di dalam ekosistem yang tercemar.

Indeks keanekaragaman fitoplankton dapat menggambarkan struktur masyarakat organisme tersebut di suatu perairan. Keanekaragaman fitoplankton akan berkurang apabila suatu komunitas yang didominansi oleh satu atau sejumlah kecil spesies (Soegianto, 2004). Tujuan dari penelitian ini untuk mengetahui komposisi, keanekaragaman dan dominansi fitoplankton sebagai pakan alami pada perairan calon suaka perikanan di Waduk Koto Panjang, Riau.

\section{BAHAN DAN METODE}

\section{Lokasi dan Waktu Penelitian}

Pengumpulan data dilakukan dengan metode survei (stratified sampling method) yaitu pengambilan contoh secara acak terstratifikasi dengan membagi populasi dalam kelompok-kelompok yang homogen di mana subyek antara satu kelompok dengan kelompok yang lain tampak ada strata atau tingkatan (Fachrul, 2007), ada 3 kali yaitu pada bulan Maret, Juni, dan Desember 2007 di Waduk Koto Panjang, Riau. Berdasarkan pada hasil penelitian Loka Riset Pemacuan Stok Ikan tahun 2007 terdapat 5 daerah calon suaka perikanan Pongkay, Muara Takus, Kuto Tuo, Gulamo, dan Osang (Gambar 1). Analisis contoh dilakukan di Laboratorium Loka Riset Pemacuan Stok Ikan. Karakteritik perairan dijelaskan secara rinci dalam Tabel 1.

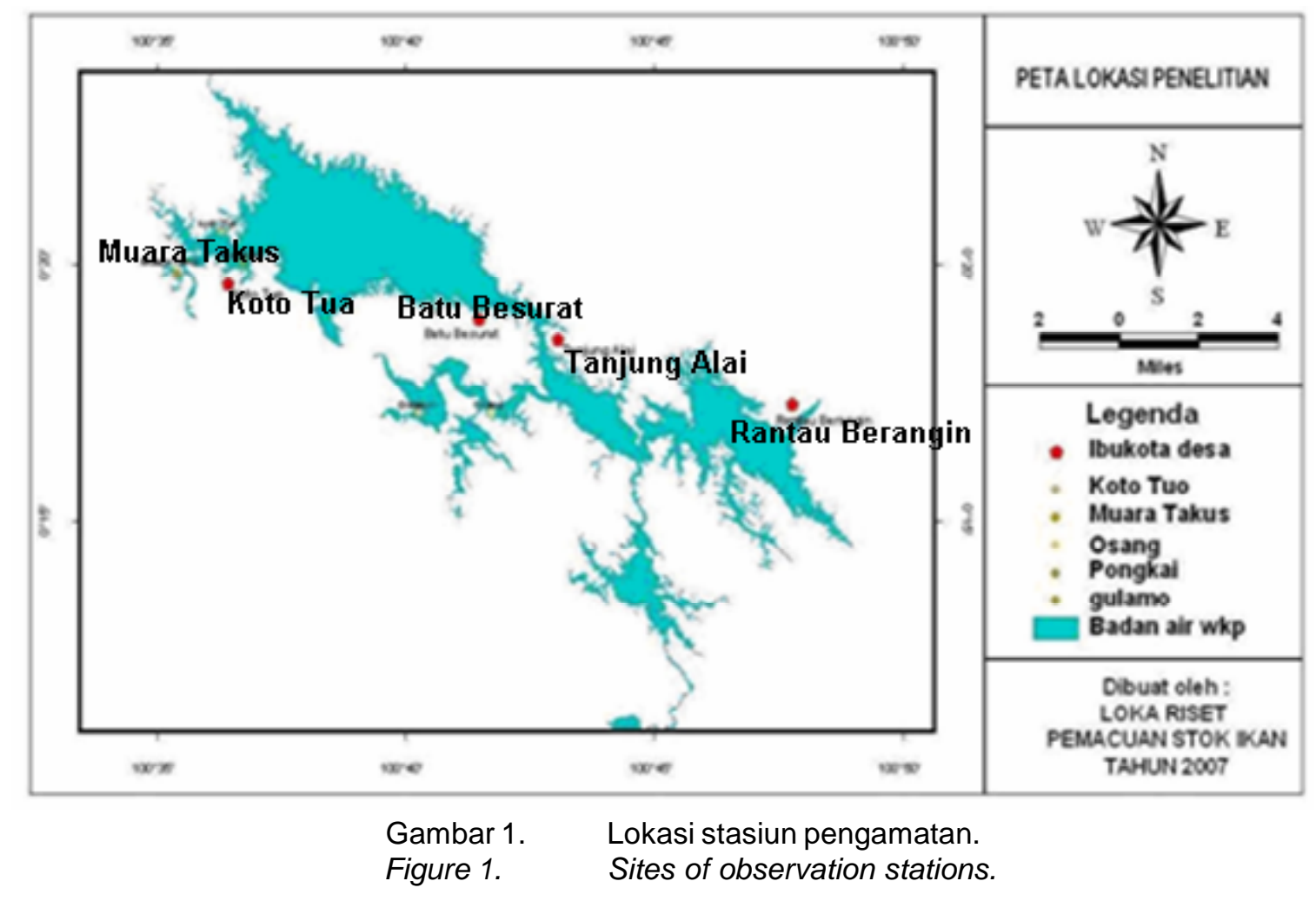

\section{Pengambilan Contoh}

\section{a. Plankton}

Sebanyak 5 - 20 L contoh air masing-masing diambil dari kedalaman 0,2 , 4, dan 8 m dengan menggunakan kemmerer water sampler, kemudian disaring memakai plankton net no. 25 (mesh size 60 $\mu \mathrm{m})$. Contoh plankton hasil penyaringan selanjutnya diawetkan dengan larutan Lugol. Pengamatan dilakukan terhadap 20 lapang pandang tanpa pengulangan pada lapang pandang yang sama dengan 
Tabel 1. Karakteristik stasiun pengambilan contoh di Waduk Koto Panjang, Riau Table 1. Characteristic of sampling stations at Koto Panjang (Riau) Reservoir

\begin{tabular}{|c|c|c|c|c|}
\hline No. & $\begin{array}{l}\text { Lokasi/ } \\
\text { Location }\end{array}$ & $\begin{array}{l}\text { Posisi/ } \\
\text { Position }\end{array}$ & $\begin{array}{l}\text { Deskripsi lokasi/ } \\
\text { Locations description }\end{array}$ & $\begin{array}{l}\text { Potret/ } \\
\text { Figure }\end{array}$ \\
\hline & Pongkey & $\begin{array}{l}\mathrm{N}: 00^{\circ} 22^{\prime} 060^{\prime} \\
\mathrm{E}: 100^{\circ} 42^{\prime} 013^{\prime}\end{array}$ & $\begin{array}{l}\text { Terdapat sungai kecil sebagai sumber air, } \\
\text { saat kemarau tidak kering (kedalaman } \pm 8 \\
\text { m), tetapi bagian muara kering jika kemarau } \\
\text { panjang, sedikit aktivitas penangkapan, saat } \\
\text { awal musim penghujan merupakan tempat } \\
\text { pemijahan. }\end{array}$ & \\
\hline 2. & Muara Takus & $\begin{array}{l}\mathrm{N}: 00^{\circ} 20^{\prime} 49.8^{\prime \prime} \\
\mathrm{E}: 100^{\circ} 39^{\prime} 51.2^{\prime \prime}\end{array}$ & $\begin{array}{l}\text { Merupakan bagian dari Sungai Kampar, } \\
\text { banyak aktivitas penangkapan, vegetasi tepi } \\
\text { didominansi oleh tumbuhan berduri dan } \\
\text { terendam pada musim hujan, yang menjadi } \\
\text { habitat pemijahan, tapak asuhan dan tapak } \\
\text { mencari makan. }\end{array}$ & \\
\hline & Kuto Tuo & $\begin{array}{l}\mathrm{N}: 00^{\circ} 21^{\prime} 33,4^{\prime \prime} \\
\mathrm{E}: 100^{\circ} 41^{\prime} 31,5^{\prime \prime}\end{array}$ & $\begin{array}{l}\text { Merupakan perairan yang luas dengan teluk- } \\
\text { teluk kecil, ketika kemarau tidak kering, } \\
\text { sungai sebagai inlet relatif besar, banyak } \\
\text { aktivitas penangkapan, vegetasi pantai } \\
\text { merupakan tumbuhan tingkat tinggi yang } \\
\text { terendam ketika musim penghujan. }\end{array}$ & \\
\hline 4. & Gulamo & $\begin{array}{l}\mathrm{N}: 00^{\circ} 16^{\prime} 39.4^{\prime \prime} \\
\mathrm{E}: 100^{\circ} 44^{\prime} 44.4^{\prime \prime}\end{array}$ & $\begin{array}{l}\text { Daerah sekitar merupakan hutan, mendapat } \\
\text { pasokkan air dari sungai gulamo, tidak } \\
\text { pernah kering ketika kemarau, di tepian } \\
\text { banyak terdapat tumbuhan mati dan } \\
\text { rerumputan jenis graminae; aktivitas } \\
\text { penangkpan sedikit. }\end{array}$ & \\
\hline 5. & Osang & $\begin{array}{l}\text { N: } 00^{\circ} 16^{\prime} 38.7^{\prime \prime} \\
\text { E: } 100^{\circ} 44^{\prime} 449^{\prime \prime}\end{array}$ & $\begin{array}{l}\text { Aktivitas penangkapan sedikit, tidak pernah } \\
\text { kering, inlet sungai osang, daerah sekitar } \\
\text { merupakan hutan, banyak terdapat } \\
\text { tumbuhan tingkat tinggi yang telah mati. }\end{array}$ & \\
\hline
\end{tabular}

menggunakan mikroskop binokuler pada pembesaran 100 kali. Rujukkan yang digunakan untuk identifikasi fitoplankton adalah Whiple (1947); Edmonson (1959), Needham \& Needham (1963), dan Sachlan (1982).

Perhitungan kelimpahan fitoplankton dilakukan dengan menggunakan metode lackey drop microtransect counting (American Public Health Association, 1989), rumusnya adalah sebagai berikut:

$$
N=n \times \frac{A}{B} \times \frac{C}{D} \times \frac{1}{E}
$$

di mana:

$$
\begin{aligned}
& \mathrm{N}=\text { jumlah total plankton (ind. per } \mathrm{L}) \\
& \mathrm{n}=\text { jumlah rata-rata individu per lapang pandang } \\
& A=\text { luas gelas penutup }\left(\mathrm{mm}^{2}\right) \\
& B=\text { luas satu lapang pandang }\left(\mathrm{mm}^{2}\right) \\
& C=\text { volume air terkonsentrasi }(\mathrm{ml}) \\
& D=\text { volume satu tetes }(\mathrm{ml}) \\
& E=\text { volume air yang disaring }(\mathrm{L})
\end{aligned}
$$

Indeks keanekaragaman fitoplankton dihitung dengan menggunakan persamaan Shanon-Wiener. Perhitungan ini menggambarkan analisis informasi mengenai jumlah individu serta berapa banyak jenis yang ada dalam suatu komunitas. Rumus perhitungan (Odum, 1971) yang digunakan adalah sebagai berikut:

$$
H^{\prime}=-\sum_{i}^{n} p i \ln p i
$$

di mana:

$$
\begin{aligned}
& H^{\prime}=\text { indeks keaneakragaman Shanon-Wiener } \\
& p_{i}=\text { ni/N } \\
& n i=\text { jumlah individu jenis ke-i } \\
& N=\text { jumlah seluruh individu }
\end{aligned}
$$

Berdasarkan pada formulasi di atas, maka kriteria baku mutu planktonologis menurut indeks keanekaragaman Shannon-Wiener (Tabel 2). 
Tabel 2. Kriteria baku mutu kualitas air berdasarkan pada indeks keanekaragaman fitoplankton Table 2. Standard criteria of water quality based on the diversity index of phytoplankton community

\begin{tabular}{|c|c|}
\hline $\begin{array}{l}\text { Indeks keanekaragaman seluruh komunitas } \\
\text { fitoplankton (metode Shannon-Wiener)/ } \\
\text { Diversity index of whole fitoplankton } \\
\text { communities (Shannon-Wiener method) }\end{array}$ & $\begin{array}{c}\text { Petunjuk/ } \\
\text { Criteria }\end{array}$ \\
\hline$>2,5$ & $\begin{array}{l}\text { Kondisi lingkungan sangat baik dan tidak tercemar. Proses } \\
\text { biogeokimiawi; terutama untuk zat hara perairan; berjalan baik. } \\
\text { Tidak ada salah satu marga atau jenis fitoplankton yang } \\
\text { mendominansi. Anggota filum Chlorophyta dan Euglenophyta } \\
\text { berkembang dengan baik, karena pada umumnya anggota filum } \\
\text { ini jenis yang toleran. Meskipun demikian, ditemukan juga jenis- } \\
\text { jenis yang moderat. }\end{array}$ \\
\hline $1,0-2,5$ & $\begin{array}{l}\text { Kondisi lingkungan perairan sedang, dengan kandungan bahan } \\
\text { organik cukup nyata. Kandungan bahan organik ini dapat } \\
\text { berasal dari pencemaran atau sebab alamiah. Komunitas } \\
\text { fitoplankton pada umumnya tidak secara mencolok didominansi } \\
\text { oleh filum Cyanophyta atau jenis-jenis moderat lain. Filum } \\
\text { Chlorophyta dan Euglenophyta pada umumnya populasi agak } \\
\text { tertekan dan rendah keanekaragaman. Filum Cyanophyta agak } \\
\text { menonjol populasi. }\end{array}$ \\
\hline$<1$ & $\begin{array}{l}\text { Lingkungan tercemar bobot oleh bahan organik atau bahan } \\
\text { pencemar lain. Ada jenis fitoplankton yang sangat menonjol dan } \\
\text { mendominansi komunitas fitoplankton yaitu anggota- anggota } \\
\text { filum Chrysophyta. Organisme yang bertahan pada kondisi } \\
\text { buruk ini pada umumnya organisme-organisme toleran. }\end{array}$ \\
\hline
\end{tabular}

Sumber/Sources: Krebs (1992)

Indeks Dominansi dihitung dengan menggunakan formula Simpson, yaitu:

$$
D_{i}=\frac{n i}{N} \times 100 \%
$$

di mana:

$$
\begin{aligned}
& \mathrm{Di}=\text { Indeks Dominansi (\%) } \\
& \mathrm{Ni}=\text { jumlah individu tiap jenis } \\
& \mathrm{N}=\text { jumlah total individu tiap jenis }
\end{aligned}
$$

Menurut Brower \& Zarr (1997), kriteria dominansi ditentukan sebagai berikut:

$$
\begin{array}{ll}
\text { Dominan } & : \text { jika } D_{i}>5 \% \\
\text { Sub dominan } & : \text { jika } D_{i} \text { berada di antara 2- 5\% } \\
\text { Tidak dominan : } & \text { jika } D_{i}<2 \%
\end{array}
$$

\section{b. Kualitas Air}

Pengambilan contoh air dilakukan dengan menggunakan kemmerer water sampler volume $5 \mathrm{~L}$, kemudian contoh air tersebut dimasukkan ke dalam botol contoh untuk dianalisis di Laboratorium Loka Riset Pemacuan Stok Ikan. Parameter kualitas air diamati dengan metode berdasarkan pada American Public Health Association (1989) seperti dijelaskan pada Tabel 3.

\section{HASIL DAN BAHASAN}

\section{Komposisi dan Kelimpahan Fitoplankton}

Dari hasil pengamatan contoh plankton di 5 stasiun pengamatan, ditemukan 36 jenis fitoplankton. Dari pengamatan tersebut terdapat 11 jenis fitoplankton yang sering ditemukan di kelima stasiun tersebut. Komunitas fitoplankton tersebut terdiri atas tujuh jenis anggota kelas Chlorophyceae (Ankistrodesmus, Cosmarium, Radiococcus, Scenedesmus, Staurastrum, Tetraedron, dan Oocystis), dua jenis dari Bacillariophyceae (Asterionella dan Nitzchia), dan satu jenis masing-masing dari kelas Dinophyceae (Peridinium) dan Euglenophyceae (Euglena).

Kelimpahan total fitoplankton di Waduk Koto Panjang adalah $6,6 \times 10^{5}$ ind. per $L$ (Tabel 3 ). Ratarata kelimpahan total fitoplankton tertinggi ditemukan di stasiun Muara Takus $\left(1,6 \times 10^{5}\right.$ ind. per L dengan 24 jenis). Berdasarkan pada nilai kelimpahan total fitoplankton, Waduk Koto Panjang termasuk ke dalam perairan eutrofik menuju hipertrofik. Selama pengamatan, terdapat tiga jenis fitoplankton yang sangat mencolok kelimpahannya pada setiap stasiun pengamatan dibandingkan jenis lainnya yaitu Cosmarium dan Staurastrum (kelas Chlorophyceae), 
Tabel 3. Beberapa parameter fisika-kimia air yang diamati dan metode pengamatannya (American Public Health Association (1989)

Table 3. Some parameters of physical-chemical water observed and their methods (American Public Health Association (1989)

\begin{tabular}{|c|c|c|}
\hline Parameter/Parameters & Satuan/Unit & Metode/Methods \\
\hline 1. Kecerahan/Transparency & $\mathrm{cm}$ & Secchi disk \\
\hline 2. Suhu/Temperature & ${ }^{\circ} \mathrm{C}$ & Termometer \\
\hline 3. $\mathrm{Ph}$ & Unit & $\mathrm{pH}$ indicator solution 4-10 \\
\hline 4. Oksigen terlarut (Dissolved Oxygen, DO) & $\mathrm{mg} / \mathrm{L}$ & DO meter YSI 55 \\
\hline 5. Karbondiokasida bebas (Free carbon dioxide, $\mathrm{CO}_{2}$ ) & $\mathrm{mg} / \mathrm{L}$ & $\mathrm{Na}_{2} \mathrm{CO}_{3} /$ Titrimetri \\
\hline 6. Alkalinitas total & $\mathrm{mg} / \mathrm{L} \mathrm{CaCO}_{3}$ & HCl/Titimetri \\
\hline 7. $\mathrm{N}-\mathrm{NO}_{3}$ & $\mathrm{mg} / \mathrm{L}$ & Brucine sulfat/Spektrofotometri \\
\hline 8. $\mathrm{N}-\mathrm{NO}_{2}$ & $\mathrm{mg} / \mathrm{L}$ & Naftilamine/Spektrofotometri \\
\hline 9. $\mathrm{N}-\mathrm{NH}_{4}$ & $\mathrm{mg} / \mathrm{L}$ & Nessler/Spektrofotomettri \\
\hline 10. ${\mathrm{P}-\mathrm{PO}_{4}}_{4}$ & $\mathrm{mg} / \mathrm{L}$ & $\mathrm{SnCl}_{2} /$ Spektrofotometri \\
\hline 11. Bahan organik total (Total Organic Matter, TOM) & $\mathrm{mg} / \mathrm{L}$ & Kalium permanganat/Titrimetri \\
\hline
\end{tabular}

serta Peridinium (kelas Dinophyceae). Dilihat dari kelimpahan total semua stasiun pengamatan, Cosmarium merupakan jenis yang memiliki kelimpahan tertinggi dibandingkan dengan jenis Staurastrum dan Peridinium.

Indeks keanekaragaman fitoplankton di Waduk Koto Panjang berkisar 2,57 - 2,87. Nilai total indeks keanekaragaman pada semua stasiun pengamatan adalah 2,97. Nilai keanekaragaman fitoplankton di stasiun Osang lebih bervariasi dibandingkan dengan di stasiun Koto Tuo (Tabel 4).

Tabel 5 menunjukkan bahwa Cosmarium, Staurastrum, dan Peridinium dominan di stasiun Muara Pongkay, Muara Takus, dan Gulamo. Di stasiun Koto Tuo hanya Cosmarium dan Staurastrum yang dominan. Ini berbeda dengan stasiun Osang di mana hanya jenis Staurastrum yang dominan.

Dominansi kumulatif jenis fitoplankton pada Tabel 6 menunjukkan bahwa Cosmarium memiliki persentase paling tinggi, disusul Staurastrum dan yang terakhir Peridinium. Dari hasil tersebut di atas dapat diketahui bahwa keadaan lingkungan perairan di Waduk Koto Panjang tergolong baik, terlihat dari nilai Indeks Keanekaragaman yang tinggi. Kelimpahan fitoplankton yang mendominansi pun tidak melebihi $50 \%$ dari kelimpahan total. Berbeda dengan pengamatan Soedarti et al. (2006), di Waduk Sutami, Malang, kelimpahan fitoplankton mencapai $68,48 \%$, menunjukkan bahwa ketidakseimbangan lingkungan perairan yang ditandai oleh munculnya jenis-jenis tertentu yang lebih dominan terhadap jenis lain dalam komunitas. Dalam hal ini, jenis fitoplankton yang mendominansi di Waduk Sutami adalah Ceratium.

\section{Parameter Fisika Kimia}

Hasil pengukuran parameter fisika kimia perairan pada bulan Maret, Juni, dan Desember 2007 di Waduk Koto Panjang tercantum pada Tabel 7. Hasil yang disajikan merupakan rata-rata pengukuran parameter pada setiap bulannya.

Kecerahan suatu badan air sangat bergantung pada warna dan kekeruhan, merupakan ukuran transparansi perairan. Kekeruhan pada perairan yang tergenang (lentik) seperti danau dan waduk lebih banyak disebabkan oleh bahan tersuspensi yang berupa koloid dan partikel-partikel halus (Effendi, 2003). Kecerahan di waduk ini berkisar 60,0 - 200,0 $\mathrm{cm}$. Kecerahan terendah terdapat di stasiun Muara Takus yang kemungkinan disebabkan oleh tingginya kelimpahan fitoplankton dan partikel terlarut yang ditandai oleh air yang berwarna hijau keruh. Kecerahan demikian diharapkan bahwa fotosintesis oleh fitoplankton yang menghasilkan oksigen terlarut dapat berjalan dengan baik karena penetrasi cahaya dapat mencapai perairan yang dalam.

Suhu air permukaan dan dasar perairan di Waduk Koto Panjang masing-masing berkisar $26,3-32,7^{\circ} \mathrm{C}$ dan $25,0-28,6^{\circ} \mathrm{C}$. Organisme akuatik mempunyai kisaran suhu tertentu (batas atas atau bawah) yang baik untuk pertumbuhannya. Fitoplankton mampu hidup pada kisaran suhu $26,0-32,0^{\circ} \mathrm{C}$ (Pratiwi et al., 2000). Suhu di suatu badan air dipengaruhi oleh 
Tabel 4. Komposisi, kelimpahan, dan keanekaragaman fitoplankton di stasiun pengamatan di Waduk Koto Panjang, Riau

Table 4. Composition, abundance, and diversity of phytoplankton in sampling stations of Koto Panjang Reservoir, Riau

\begin{tabular}{|c|c|c|c|c|c|c|c|}
\hline \multirow[t]{2}{*}{ No. } & \multirow{2}{*}{$\begin{array}{c}\text { Kelas dan jenis } \\
\text { Fitoplankton/ } \\
\text { Class and species of } \\
\text { phytoplankton }\end{array}$} & \multicolumn{5}{|c|}{$\begin{array}{l}\text { Kelimpahan rata-rata fitoplankton pada } 5 \text { stasiun/ } \\
\text { Average abundance of phytoplanton in } 5 \text { stations } \\
\text { (ind. per I) }\end{array}$} & \multirow{2}{*}{$\begin{array}{c}\text { Total/ } \\
\text { Total }\end{array}$} \\
\hline & & $\begin{array}{c}\text { Muara } \\
\text { Pongkay }\end{array}$ & $\begin{array}{l}\text { Muara } \\
\text { Takus } \\
\end{array}$ & Koto Tuo & Osang & Gulamo & \\
\hline & \multicolumn{7}{|l|}{ Chlorophyceae } \\
\hline 1. & Actinastrum sp. & 0 & 0 & 2.012 & 1.677 & 2.012 & 5.701 \\
\hline 2. & Ankistrodesmus sp. & 3.162 & 6.036 & 5.030 & 5.701 & 5.701 & 25.629 \\
\hline 3. & Chlorella sp. & 5.785 & 6.036 & 0 & 0 & 0 & 11.821 \\
\hline 4. & Closterium sp. & 5.030 & 5.021 & 1.509 & 0 & 0 & 11.560 \\
\hline 5. & Cosmarium sp. & 30.746 & 28.839 & 35.378 & 18.360 & 14.659 & 127.981 \\
\hline 6. & Crucigenia sp. & 3.353 & 11.401 & 3.773 & 0 & 4.024 & 22.551 \\
\hline 7. & Euastrum sp. & 0 & 0 & 0 & 1.006 & 0 & 1.006 \\
\hline 8. & Pediastrum sp. & 2.012 & 0 & 3.018 & 4.024 & 4.024 & 13.078 \\
\hline 9. & Penium sp. & 0 & 0 & 3.018 & 1.006 & 2.515 & 6.539 \\
\hline 10. & Protococcus sp. & 5.533 & 8.551 & 0 & 0 & 0 & 14.084 \\
\hline 11. & Radiococcus sp. & 3.018 & 3.018 & 2.012 & 2.683 & 2.515 & 13.246 \\
\hline 12. & Scenedesmus sp. & 3.018 & 2.012 & 5.785 & 3.186 & 2.264 & 16.264 \\
\hline 13. & Spirogyra sp. & 0 & 0 & 0 & 2.012 & 0 & 2.012 \\
\hline 14. & Sorastrum sp. & 0 & 9.054 & 0 & 0 & 0 & 9.054 \\
\hline 15. & Staurastrum sp. & 24.270 & 22.333 & 23.767 & 15.342 & 15.928 & 101.640 \\
\hline 16. & Tetraedron sp. & 7.444 & 3.018 & 5.910 & 8.652 & 7.617 & 32.641 \\
\hline 17. & Truberia sp. & 4.695 & 4.024 & 8.048 & 4.024 & 0 & 20.791 \\
\hline 18. & Ulothrix sp. & 2.683 & 0 & 2.012 & 5.030 & 2.347 & 12.072 \\
\hline 19. & Xanthidium sp. & 0 & 0 & 0 & 1.006 & 0 & 1.006 \\
\hline 20. & Oocystis sp. & 5.701 & 4.695 & 3.773 & 3.773 & 3.823 & 21.763 \\
\hline 21. & $\begin{array}{l}\text { Zygnema sp. } \\
\text { Cyanophyceae }\end{array}$ & 0 & 2.012 & 0 & 0 & 0 & 2.012 \\
\hline 1. & Anabaena sp. & 2.012 & 2.012 & 4.024 & 0 & 0 & 8.048 \\
\hline 2. & Lyngbya sp. & 0 & 0 & 3.018 & 7.042 & 5.030 & 15.090 \\
\hline 3. & $\begin{array}{l}\text { Oscillatoria sp. } \\
\text { Bacillariophyceae }\end{array}$ & 0 & 8.048 & 5.785 & 4.024 & 3.353 & 21.210 \\
\hline 1. & Asterionella sp. & 2.683 & 4.024 & 3.018 & 7.419 & 6.539 & 23.683 \\
\hline 2. & Naviculla sp. & 0 & 0 & 0 & 2.515 & 1.006 & 3.521 \\
\hline 3. & Nitzschia sp. & 2.012 & 2.012 & 6.036 & 4.024 & 8.048 & 22.132 \\
\hline 4. & Pinnularia sp. & 2.012 & 2.012 & 0 & 0 & 0 & 4.024 \\
\hline 5. & Surirella sp. & 0 & 0 & 0 & 3.018 & 0 & 3.018 \\
\hline 6. & Synedra sp. & 4.024 & 0 & 0 & 0 & 0 & 4.024 \\
\hline 7. & $\begin{array}{l}\text { Tabellaria sp. } \\
\text { Dinophyceae }\end{array}$ & 4.359 & 3.018 & 0 & 0 & 0 & 7.377 \\
\hline 1. & Ceratium sp. & 2.347 & 4.024 & 0 & 0 & 0 & 6.371 \\
\hline 2. & Mallomonas sp. & 0 & 0 & 0 & 1.509 & 0 & 1.509 \\
\hline 3. & $\begin{array}{l}\text { Peridinium sp. } \\
\text { Euglenophyceae }\end{array}$ & 12.198 & 14.419 & 6.916 & 7.545 & 12.363 & 53.441 \\
\hline 1. & Euglena sp. & 2.012 & 1.006 & 1.341 & 2.012 & 2.012 & 8.383 \\
\hline 2. & Phacus sp. & 2.012 & 3.018 & 0 & 0 & 0 & 5.030 \\
\hline Kelim & pahan total (N) & 142.120 & 159.643 & 135.181 & 116.587 & 105.780 & 659.311 \\
\hline Jumla & henus & 24 & 24 & 21 & 24 & 19 & 36 \\
\hline Indek & s Keanekaragaman & 2,74 & 2,81 & 2,57 & 2,87 & 2,69 & 2,97 \\
\hline
\end{tabular}


Tabel 5. Tingkat dominansi genus fitoplankton $\left(D_{>}>5 \%\right)$ pada 5 stasiun pengambilan contoh Table 5. The level of dominanan phytoplankton genus $\left(D_{1}>5 \%\right)$ at five sampling stations

\begin{tabular}{|c|c|c|c|c|c|c|c|c|c|}
\hline \multicolumn{2}{|c|}{ Muara Pongkay } & \multicolumn{2}{|c|}{ Muara Takus } & \multicolumn{2}{|c|}{ Koto Tuo } & \multicolumn{2}{|c|}{ Osang } & \multicolumn{2}{|c|}{ Gulamo } \\
\hline Genus & $\begin{array}{c}\mathrm{Di} \\
(\%)\end{array}$ & Genus & $\begin{array}{l}\mathbf{D i} \\
(\%)\end{array}$ & Genus & $\begin{array}{c}\mathbf{D i} \\
(\%)\end{array}$ & Genus & $\begin{array}{c}\mathrm{Di} \\
(\%)\end{array}$ & Genus & $\begin{array}{l}\mathbf{D i} \\
(\%)\end{array}$ \\
\hline Cosmarium & 30,35 & imarium & $30, \varepsilon$ & osmariun & 1,08 & Staurastum & 24 & Cosmarium & 20,90 \\
\hline Staurastrum & 27,38 & taurastrum & 19,8 & taurastruı & 7,84 & & & Staurastrum & 19,47 \\
\hline Peridinium & 13,76 & eridinium & 15,4 & & & & & Peridinium & 17,63 \\
\hline
\end{tabular}

Tabel 6. Indeks Dominansi kumulatif fitoplankton dari 5 stasiun pengambilan contoh Table 6. Index of dominance phytoplankton cummulative from five sampling stations

\begin{tabular}{lcc}
\hline \multicolumn{1}{c}{ Genus } & $\begin{array}{c}\text { Kelimpahan total/ } \\
\text { Total abundance }\end{array}$ & $\begin{array}{c}\text { Dominansi kumulatif/ } \\
\text { Commulative dominance (\%) }\end{array}$ \\
\hline Smarium & 106.114 & 26,54 \\
Staurastrum & 95.642 & 23,92 \\
Peridinium & 53.441 & 13,37 \\
\hline
\end{tabular}

Tabel 7. Nilai parameter fisika kimia perairan Waduk Koto Panjang, Riau, bulan Maret, Juni, dan Desember 2007

Table 7. The values physico chemical parameter values at Koto Panjang (Riau) Reservoir in March, June, and December 2007

\begin{tabular}{|c|c|c|c|c|c|c|}
\hline \multirow{3}{*}{ No. } & \multirow{3}{*}{$\begin{array}{l}\text { Parameter/ } \\
\text { Parameters }\end{array}$} & \multicolumn{5}{|c|}{ Stasiun/Stations } \\
\hline & & Pongkay & Muara Takus & Kuto Tuo & Osang & Gulamo \\
\hline & & $\begin{array}{c}\text { Kisaran } \\
\text { (Rata-rata) }\end{array}$ & $\begin{array}{c}\text { Kisaran } \\
\text { (Rata-rata) }\end{array}$ & $\begin{array}{c}\text { Kisaran } \\
\text { (Rata-rata) }\end{array}$ & $\begin{array}{c}\text { Kisaran } \\
\text { (Rata-rata) }\end{array}$ & $\begin{array}{c}\text { Kisaran } \\
\text { (Rata-rata) }\end{array}$ \\
\hline 1. & Kecerahan $(\mathrm{cm})$ & $\begin{array}{c}130-200 \\
(160)\end{array}$ & $\begin{array}{c}60-110 \\
(103)\end{array}$ & $\begin{array}{c}120-160 \\
(136)\end{array}$ & $\begin{array}{c}120-180 \\
(120)\end{array}$ & $\begin{array}{c}100-160 \\
(150)\end{array}$ \\
\hline 2. & Suhu air $\left({ }^{\circ} \mathrm{C}\right)$ & $\begin{array}{c}27,3-31,8 \\
(28,3)\end{array}$ & $\begin{array}{c}25,1-31,8 \\
(27,4)\end{array}$ & $\begin{array}{c}26,3-32,7 \\
(28,1)\end{array}$ & $\begin{array}{c}27,1-31,0 \\
(30,4)\end{array}$ & $\begin{array}{c}25,9-30,4 \\
(28,2)\end{array}$ \\
\hline 3. & $\mathrm{pH}$ (unit) & $\begin{array}{c}6,0-7,5 \\
(7,0)\end{array}$ & $\begin{array}{c}6,5-7,0 \\
(7,0)\end{array}$ & $\begin{array}{c}6,5-7,5 \\
(7,0)\end{array}$ & $\begin{array}{r}5,5-7 \\
(6,0)\end{array}$ & $\begin{array}{c}5,5-7,5 \\
(6,5)\end{array}$ \\
\hline 4. & $\mathrm{DO}(\mathrm{mg} / \mathrm{L})$ & $\begin{array}{c}2,20-8,57 \\
(5,80)\end{array}$ & $\begin{array}{c}1,52-8,76 \\
(5,02)\end{array}$ & $\begin{array}{c}1,52-8,76 \\
(5,11)\end{array}$ & $\begin{array}{c}0,84-5,43 \\
(3,81)\end{array}$ & $\begin{array}{c}1,31-5,93 \\
(3,87)\end{array}$ \\
\hline 5. & $\mathrm{CO}_{2}(\mathrm{mg} / \mathrm{L})$ & $\begin{array}{c}2,73-8,50 \\
(84,30)\end{array}$ & $\begin{array}{c}2,73-5,72 \\
(3,15)\end{array}$ & $\begin{array}{c}2,73-8,58 \\
(5,19)\end{array}$ & $\begin{array}{c}2,73-8,58 \\
(4,75)\end{array}$ & $\begin{array}{c}2,73-11,44 \\
(4,03)\end{array}$ \\
\hline 6. & $\begin{array}{l}\text { Alkalinitas total }(\mathrm{mg} / \mathrm{L} \\
\left.\text { eq } \mathrm{CaCO}_{3}\right)\end{array}$ & $\begin{array}{c}10,56-27,30 \\
(18,52)\end{array}$ & $\begin{array}{c}13,22-31,25 \\
(20,21)\end{array}$ & $\begin{array}{c}13,2-224,72 \\
(18,78)\end{array}$ & $\begin{array}{c}7,8-17,29 \\
(12,69)\end{array}$ & $\begin{array}{c}7,8-17,29 \\
(12,19)\end{array}$ \\
\hline 7. & $\mathrm{~N}-\mathrm{NO}_{2}(\mathrm{mg} / \mathrm{L})$ & $\begin{array}{c}0,001-0,053 \\
(0,016)\end{array}$ & $\begin{array}{c}0,004-0,045 \\
(0,015)\end{array}$ & $\begin{array}{c}0,000-0,006 \\
(0,013)\end{array}$ & $\begin{array}{c}0,000-0,062 \\
(0,018)\end{array}$ & $\begin{array}{c}0,005-0,033 \\
(0,0213)\end{array}$ \\
\hline 8. & $\mathrm{~N}-\mathrm{NO}_{3}(\mathrm{mg} / \mathrm{L})$ & $\begin{array}{c}0,058-3,765 \\
(1,010)\end{array}$ & $\begin{array}{c}0,23-2,203 \\
(0,753)\end{array}$ & $\begin{array}{c}0,083-2,128 \\
(1,042)\end{array}$ & $\begin{array}{c}0,047-2,612 \\
(0,852)\end{array}$ & $\begin{array}{c}0,058-2,401 \\
(0,916)\end{array}$ \\
\hline 9. & $\mathrm{~N}-\mathrm{NH}_{4}(\mathrm{mg} / \mathrm{L})$ & $\begin{array}{c}0,604-10,15 \\
(4,662)\end{array}$ & $\begin{array}{c}0,591-7,853 \\
(2,744)\end{array}$ & $\begin{array}{c}0,755-6,736 \\
(2,643)\end{array}$ & $\begin{array}{c}0,846-6,107 \\
(3,6921)\end{array}$ & $\begin{array}{c}1,0952-9,694 \\
(2,972)\end{array}$ \\
\hline 10. & $\mathrm{P}-\mathrm{PO}_{4}(\mathrm{mg} / \mathrm{L})$ & $\begin{array}{c}0,000-0,338 \\
(0,082)\end{array}$ & $\begin{array}{c}0,018-0,107 \\
(0,071)\end{array}$ & $\begin{array}{c}0,000-0,374 \\
(0,125)\end{array}$ & $\begin{array}{c}0,006-2,927 \\
(0,071)\end{array}$ & $\begin{array}{c}0,031-0,125 \\
(0,331)\end{array}$ \\
\hline 11. & TOM (mg/L) & $\begin{array}{c}1,67-10,49 \\
(10,49)\end{array}$ & $\begin{array}{c}0,53-4,8 \\
(0,28)\end{array}$ & $\begin{array}{c}1,39-5,65 \\
(3,36)\end{array}$ & $\begin{array}{c}0,25-7,64 \\
(3,02)\end{array}$ & $\begin{array}{c}0,82-4,51 \\
(3,35)\end{array}$ \\
\hline
\end{tabular}

beberapa faktor antara lain ketinggian dari permukaan laut, waktu dalam hari, sirkulasi udara, penutupan awan, aliran-aliran, serta kedalaman badan air. Peningkatan suhu $10^{\circ} \mathrm{C}$ akan meningkatan penggunaan oksigen oleh organisme akuatik sekitar 2,0 - 3,0 kali lipat (Effendi, 2003).
Di permukaan, konsentrasi DO berkisar 5,43 - 8,76 $\mathrm{mg} / \mathrm{L}$. Konsentrasi DO di permukaan cukup tinggi karena fotosintesis oleh fitoplankton berjalan dengan baik. Kemungkinan Waduk Koto Panjang mempunyai kelimpahan fitoplankton berklorofil cukup tinggi yang ditandai oleh warna airnya yang hijau. Konsentrasi 
DO di dasar perairan berkisar 0,84 - 6,12 mg/L. Konsentrasi $\mathrm{DO}$ yang rendah pada umumnya terdapat di dasar perairan yang kemungkinan oksigen yang ada digunakan untuk dekomposisi bahan organik yang menghasilkan $\mathrm{CO}_{2}$ bebas. Pada lokasi yang dangkal (sekitar $4 \mathrm{~m}$ ) terjadi pada bulan Desember di stasiun Muara Takus, dasar perairan mempunyai konsentrasi DO 6,12 mg/L). Sumber DO ini kemungkinan selain berasal dari fotosintesis, juga difusi dari atmosfer. Stratifikasi DO terjadi pada bulan Juni dan Desember di stasiun Pongkay pada kedalaman 7,0 - 9,0 m. Di stasiun Osang, stratifikasi DO terjadi pada kedalaman 4,0 - 5,0 m pada setiap pengamatan (Gambar 2).
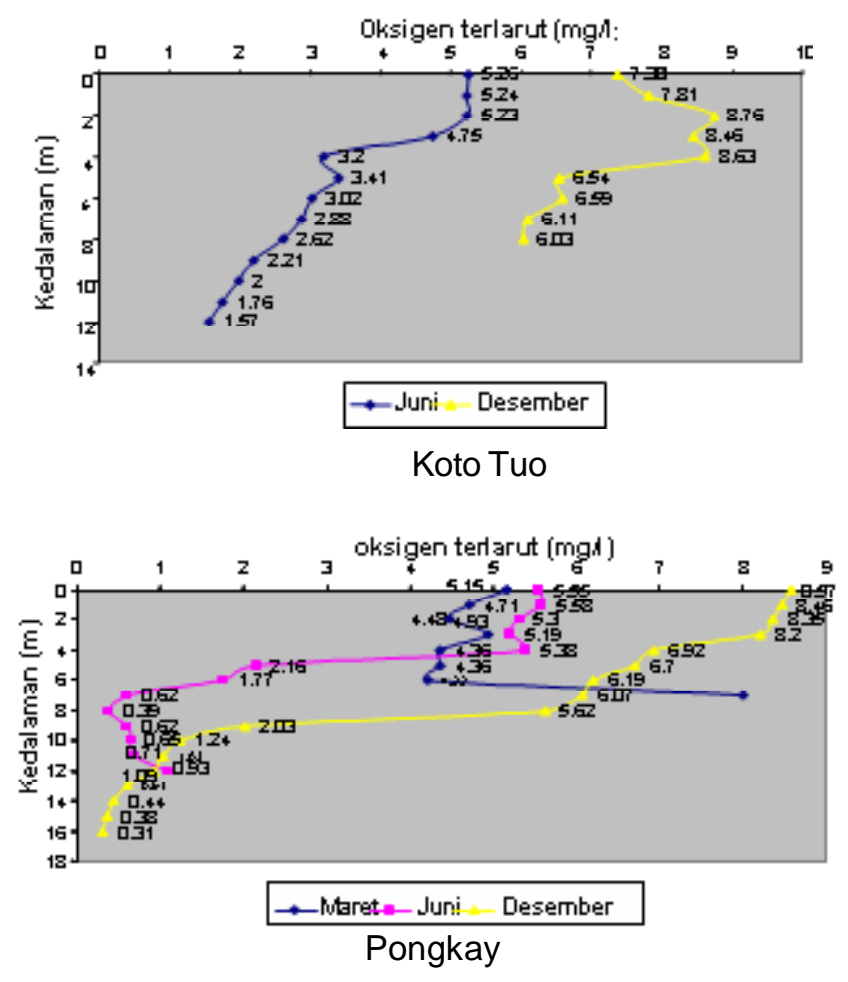

Konsentrasi $\mathrm{CO}_{2}$ bebas di permukaan dan dasar perairan masing-masing berkisar 2,73 - 5,72 dan 2,73 - 11,44 mg/L. Konsentrasi $\mathrm{CO}_{2}$ yang mendukung kegiatan perikanan adalah $<5 \mathrm{mg} / \mathrm{L}$ dan maksimal 15 $\mathrm{mg} / \mathrm{L}$ (Boyd, 1982). Konsentrasi $\mathrm{CO}_{2}$ bebas tinggi pada umumnya terdapat di dasar perairan yang kemungkinan disebabkan oleh dekomposisi bahan organik. Konsentrasi bahan organik di lokasi calon suaka perikanan Waduk Koto Panjang berkisar 0,25 - 7,64 mg/L. Bahan organik tersebut kemungkinan berasal dari tumbuhan tingkat tinggi yang telah mati dan terendam di dalam air.
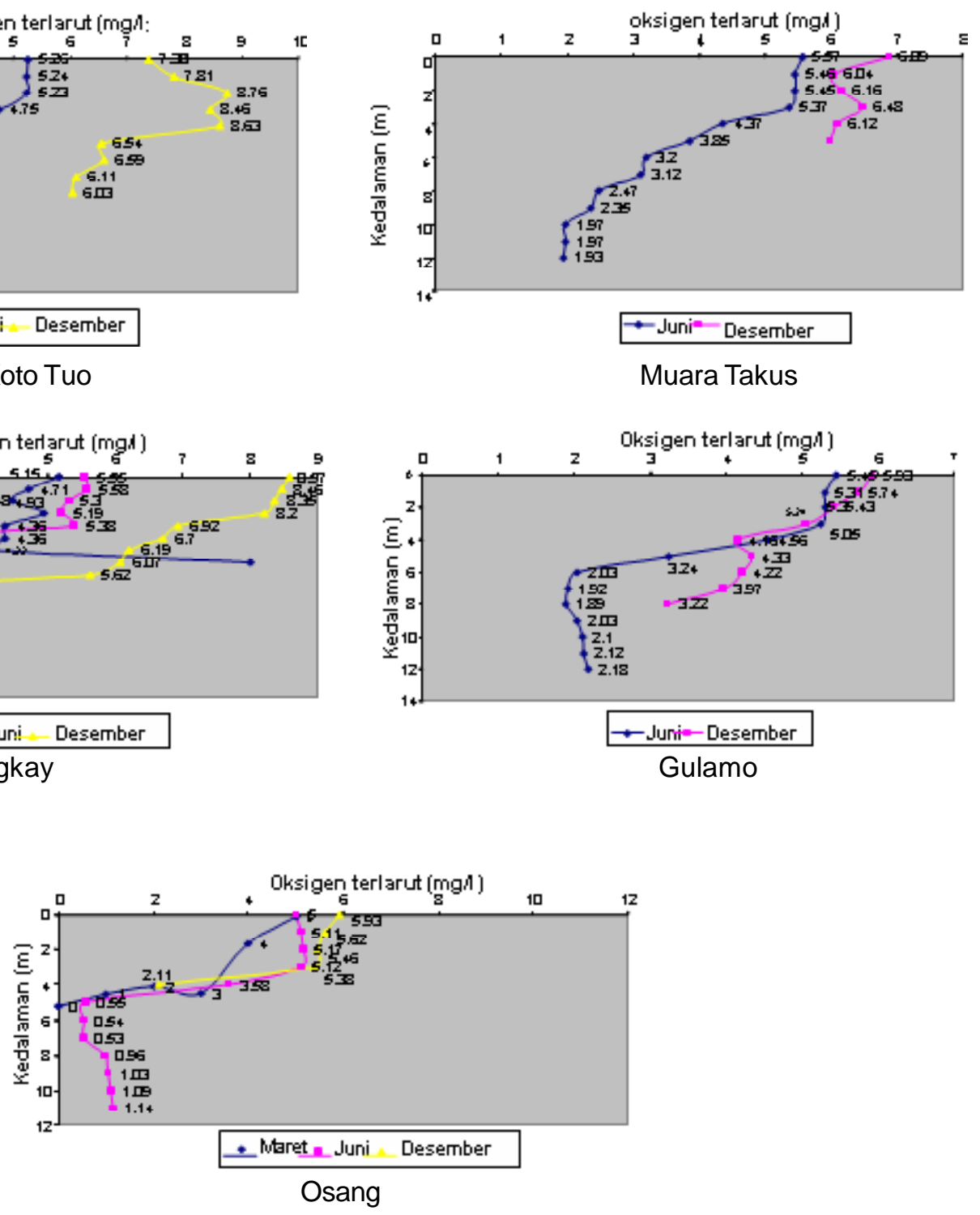

Gambar 2. Pola stratifikasi konsentrasi DO di Waduk Koto Panjang, Riau. Figure 2. Patterns of DO strafification in Koto Panjang Reservoir, Riau. 
Nilai pH peairan Waduk Koto Panjang berkisar 5,5 - 7,5, cenderung netral. pH asam pada umumnya terdapat di dasar perairan di hampir semua stasiun. Stasiun Osang pada bulan Juni memiliki pH cenderung asam, berkisar 5,5 - 6,5. Hal ini diduga disebabkan oleh konsentrasi $\mathrm{CO}_{2}$ yang tinggi. $\mathrm{pH}$ suatu perairan berkaitan erat dengan konsentrasi $\mathrm{CO}_{2}$ bebas dan nilai alkalinitas. Nilai $\mathrm{pH}$ yang mendukung untuk kehidupan biota air berkisar 6,0 - 9,0 (Effendi, 2003).

Konsentrasi $\mathrm{N}-\mathrm{NO}_{3}$ di Waduk Koto Panjang berkisar $0,047-3,765 / \mathrm{L}$. Konsentrasi $\mathrm{N}-\mathrm{NO}_{3}$ yang sesuai untuk kegiatan perikanan adalah maksimal 10 $\mathrm{mg} / \mathrm{L}$ (PP No.82 tahun 2001). Konsentrasi N-NO berkisar 0,000- 0,062 mg/L. Untuk kegiatan perikanan, konsentrasi $\mathrm{N}-\mathrm{NO}_{2}$ yang disarankan adalah maksimum 0,06 mg/L (PP No.82 tahun 2001). Konsentrasi nitrat dan nitrit di Waduk Koto Panjang memenuhi baku mutu untuk perikanan.

Amonia terdiri atas dua macam, yaitu $\mathrm{N}-\mathrm{NH}_{3}$ yang merupakan bentuk ammonia bebas dan $\mathrm{N}-\mathrm{NH}_{4}{ }^{+}$yang merupakan ammonia terionisasi. $\mathrm{N}-\mathrm{NH}_{4}{ }^{+}$merupakan bentuk yang langsung dapat dimanfaatkan oleh tumbuhan akuatik dan mudah diasimilasi di wilayah tropogenik (Effendi, 2003). Amonia dan garam-garam bersifat mudah larut dalam air. Konsentrasi $\mathrm{N}-\mathrm{NH}_{4}{ }^{+} \mathrm{di}$ Waduk Koto Panjang berkisar 0,591 - 10,15 mg/L.

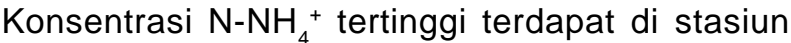
Pongkay yang kemungkinan berasal dari dekomposisi bahan organik dari limpasan tanah pucuk dan tumbuhan air yang telah mati. Amonium dapat juga berasal dari limbah bahan organik (Wetzel, 2001). Konsentrasi bahan organik di Waduk Koto Panjang berkisar 0,25 - 10,49 mg/L dengan rata-rata $3,51 \mathrm{mg} /$ L. Hal itu disebabkan oleh banyaknya tumbuhan mati yang terendam di waduk tersebut.

Konsentrasi ortofosfat di Waduk Koto Panjang berkisar $0,000-2,927 \mathrm{mg} / \mathrm{L}$. Nilai tertinggi terdapat di Osang ( $2,927 \mathrm{mg} / \mathrm{L})$. Konsentrasi ortofosfat yang tinggi pada umumnya terdapat di dasar perairan yang kemungkinan diakibatkan oleh dekomposisi bahan organik. Pendapat Mackentum (1969) dalam Yuliana \& Thamrim (2006), pertumbuhan optimal fitoplankton memerlukan ortofospat $0,09-1,8 \mathrm{mg} / \mathrm{L}$.

\section{KESIMPULAN}

Berdasarkan pada hasil pengamatan di Waduk Koto Panjang, Riau ditemukan lima kelas fitoplankton yaitu Chlorophyceae (21 marga), Cyanophyceae (3 marga), Bacillariophyceae (7 marga), Dinophyceae (3 marga), dan Euglenophyceae (2 marga) dengan total kelimpahan fitoplankton 659.311 ind./L. Total nilai Indeks Keanekaragaman selama pengamatan adalah
2,97, berarti bahwa kondisi lingkungan di Waduk Koto Panjang, Riau sangat baik dan tidak tercemar. Terdapat tiga jenis fitoplankton yang mendominansi yaitu Cosmarium, Staurastrum, dan Peridinium dengan nilai dominansi kumulatifnya masing-masing 26,54; 23,92 ; dan 13,37\%. Ketersediaan fitoplankton di Waduk Koto Panjang terutama di daerah calon suaka pada umumnya mencukupi yang mana fitoplankton tersebut dapat dimanfaatkan oleh biota lain sebagai sumber pakan alami.

\section{PERSANTUNAN}

Kegiatan dari hasil riset rehabilitasi populasi ikan di Waduk Koto Panjang, Riau, T. A. 2007, di Loka Riset Pemacuan Stok Ikan, Jatiluhur-Purwakarta.

\section{DAFTAR PUSTAKA}

American Public Health Association. 1989. Standard Methods for the Examination of Water and Waste Water. $17^{\text {th }}$ ed. American Public Health Association. Washington, D. C. 1.193 pp.

Boyd, C. E. 1982. Water Quality Management for Ponds and Fish Culture. Elsevier Scientific Publishing. New York. 359 pp.

Brower, J. E. \& J. Zarr. 1997. Field and Laboratory Methods for General Ecology. W. M. C Brown Company Publishing. Portugue. IOWA.

Edmonson, W. T. 1959. Freshwater Biology. $2^{\text {nd }}$ Ed. John Wiley \& Sonc. Inc. New York. 1.248 pp.

Effendi, H. 2003. Telaah Kualitas Air: Bagi Pengelolaan Sumber Daya dan Lingkungan Perairan. Kanisius. Yogyakarta. 259 pp.

Fachrul, M. F. 2007. Metode Sampling Bioekologi. Bumi Aksara. Jakarta.

Krebs, C. J. 1992. Ecology. The Experimental Analysis of Distribution and Abundance. Harper International Edition. Harper and Raw Publisher. New York. 694 pp.

Needham, J. G. \& P. R. Needham. 1963. A Guide to the Study of Freshwater Biology. Fifth Edition. Revised and Enlarged. Holden Day. Inc. San Fransisco. 180 pp.

Odum, E. P. 1971. Fundamental of ecology. W. B. Saunders Company. Philadelphia-London Toronto. $574 \mathrm{pp}$. 
Pratiwi, N. T. M, E. M. Adiwilaga, M. Krisanti, \& H. D. Winarni. 2006. Distribusi spasial fitoplankton pada kawasan karamba jaring apung di Waduk Ir. H. Djuanda, Jatiluhur, Purwakarta, Jawa Barat. Prosiding Seminar Nasional Limnologi. Pusat Penelitian Limnologi, LIPI. Bogor. Hal. 222-240.

Sachlan, M. 1982. Planktonologi. Fak.Peternakan dan Perikanan. Univ. Diponegoro. Semarang. 156 pp.

Soedarti, T., J. Aristiana, \& A. Soegianto. 2006. Diversitas fitoplankton pada ekosistem perairan Waduk Sutami, Malang. Berkas Penelitian Hayati. 11. 97-103.

Soegianto, A. 2004. Metode Analisis Pendugaan Pencemaran Perairan dengan Indikator Biologis. Airlangga University. Press. Surabaya.

Utomo, A. D., M. T. D Sunarno, \& S. Adjie. 2005. Teknik peningkatan produksi perikanan umum di rawa banjiran melalui penyediaan suaka perikanan. Prosiding Forum Perairan Umum I. Makalah Penunjang. Dep.Kelautan dan Perikanan. BRKP. PRPT. Jakarta. 185-192 pp.
Wiadnyana, N. N. \& A. Wagey. 2004. Plankton, Produktivitas, dan Ekosistem Perairan. Pusat Penelitian Oseanografi, LIPI. Jakarta.

Wetzel, R. G. 2001. Limnology Lake and River Ecosystem. Third Edition. Academic Press. California. $286 \mathrm{pp}$.

Whipple, G. C. 1947. The Microscopy of Drinking Water. John Wiley \& Sons. Inc. London. Chapman \& Hall. Limited. 586 pp.

Yuliana \& Tamrin. 2006. Struktur komunitas dan kelimpahan fitoplankton dalam kaitannya dengan parameter fisika kimia perairan di Danau Laguna, Ternate, Maluku Utara. Prosiding Seminar Nasional Limnologi 2006: Pengelolaan Sumber Daya Perairan Darat secara Terpadu di Indonesia. Pusat penelitian Limnologi. Jakarta. 